\title{
TRANSVERSE TESTICULAR ECTOPIA
}

1. Consultant Surgeon, CMH Malir

Correspondence Address: Dr. Fayyaz Ahmad Orfi

Consultant Surgeon,

$\mathrm{CMH}$ Malir

fayyaz_ao@hotmail.com

Article received on:

11/03/2016

Accepted for publication:

15/04/2016

Received after proof reading: 04/05/2016

\section{Dr. Fayyaz Ahmad Orfi', Dr. Saira Shakeel ${ }^{2}$, Dr. Farrukh Shahzad ${ }^{3}$}

\begin{abstract}
Crossed testicular ectopia (CTE) is a rare congenital anomaly ${ }^{14}$. It is also known as transverse testicular ectopia (TTE). In this condition both testis descend/migrate towards the same hemi-scrotum. About 100 cases have been reported so far. It may be associated with other congenital anomalies which include persistent Mullerian Duct Syndrome, true hermaphroditism, pseudo-hermaphroditism, inguinal hernia, hypospadias and scrotal anomalies. We are reporting one such case in 6 years old boy who presented to $\mathrm{CMH}$ Malir in March 2014 with left inguinal hernia and per-operatively found to have right testis in left inguinal canal. Left testis had descended into left upper scrotum. Vasa were tethered together in upper portion by fibrous tissue. Right testis and vas was separated, mobilized extra-peritonially and done in right scrotum (ipsilateral). Left orchiopexy was done in left scrotum. Hernia repair was then preformed. Post-op u/s scan was done to detect any other associated pathology which was negative. In most of the published reports diagnosis was made per-operatively as was the case in this patient.
\end{abstract}

Key words: $\quad$ Testis, Undescended testis, Cryptorchidism, Ectopic, Hemi-scrotum, TTE

Article Citation: Orfi FA, Shakeel S, Shahzad F. Transverse testicular ectopia. Professional Med J 2016;23(5):627-629. DOI: 10.17957/TPMJ/16.3338

\section{INTRODUCTION}

Transverse testicular ectopia (TTE) is a rare condition, (about 100 cases reported so far) ${ }^{1}$. It is also named crossed testicular ectopia, testicular pseudo-duplication, unilateral double testis and transverse aberrant testicular maldescent. In this condition both testis descend through the same inguinal canal towards the same hemi-scrotum. In published reports it is usually the right testis which traverses the left inguinal canal. However reports are also there in which left testis had descended towards right hemi-scrotum. Pre-operative localization on ultrasound by an experienced sinologist may be helpful but diagnosis is usually made during surgical exploration for hernia repair.

\section{CASE PRESENTATION}

A 06 year old boy presented to Combined Military Hospital (CMH Malir) in Mar 2015 with a lump in left inguinal region which increased in size on straining. It was reducible and cough impulse was present. Left testis was palpable in left upper scrotum. Right testis was not palpable. Diagnosis of left inguinal hernia with undescended right testis was made. Birth history was normal spontaneous vaginal delivery at home. Herniorrhaphy planned as first stage as this was the presenting complaint. During operation another well-developed testis was found in left inguinal canal close to the internal ring in addition to the left testis which was descended in left upper scrotum. Vigilant dissection revealed that its blood supply and vas were coming from right side. The two vas were adherent with fibrous tissue but clearly separate. Two vas were separated and right testis was mobilized extraperitoneally around the root of

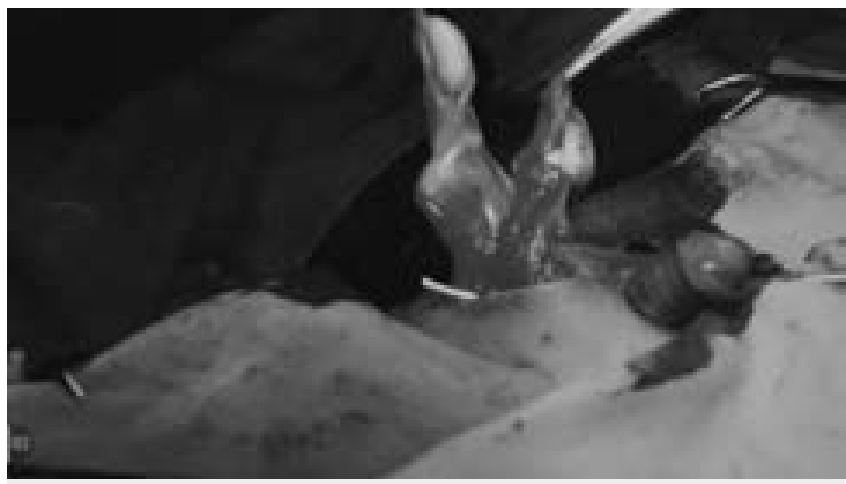

Figure-1. Both testes seen in the left hemi-scrotum 
penis. Right orchiopexy was done in ipsilateral right hemi-scrotum. Left orchiopexy was done too and hernial defect was repaired. Post-op ultrasound of abdomen and pelvis did not reveal any abnormality.

\section{DISCUSSION}

TTE is a rare clinical entity. Usual sites of ectopic testes are perineum, thigh, and anterior abdominal wall. Opposite inguinal canal and scrotum are the rare sites of ectopia. The testis migrates to the opposite side inguinal canal instead of the same side. It was first described by Van Len Hossek in1886.Several theories have been reported to explain the genesis of TTE. Berg ${ }^{2}$ proposed the possibility of development of both testes from the same genital ridge. Kimura found that if both vas deferens arise from one side, there had been unilateral origin but if there was bilateral origins, one testes had crossed over. Gupta and Das postulated that adherence and fusion of the developing Wolffian duct might have occurred which resulted in the descent of both testis to the same side. ${ }^{9}$

Another theory is that descending testis instead of following the main gubernaculum during descend to the ipsilateral hemi-scrotum, follows one of the additional branches of gubernaculum and ends up at ectopic site. One such branch goes to the opposite inguinal canal and contralateral hemiscrotum. Following this branch will result in TTE. Inguinal hernia is almost invariably present on the side to which the ectopic testis has migrated.

\section{TTE has been classified in to three types:}

Type I Accompanied only by hernia (40-50\%). Type II Accompanied by persistent or rudimentary Mullerian duct structures (30\%).

Type III Associated with anomalies like hypospadias, pseudohermaphroditism and scrotal anomalies (20\%), other urinary tract anomalies.

According to this classification, our case was of type I TTE. Association with fused vas deferens is extremely rare. This condition obstructs the ipsilateral orchiopexy during surgery. Mean age of presentation is 4 years. Few cases have been reported among adults (late diagnosis) Clinical presentation is usually with inguinal hernia with contralateral or bilateral cryptorchidism. Contralateral undescended testis is typical but usually missed because of the rarity of this condition. Diagnosis is made generally at surgical exploration as was there in our case. Pre-operative ultrasound by an experienced sonologist might help. Laparoscopy maybe helpful in both diagnosis and treatment of TTE. Patients with TTE are at increased risk of germ cell testicular tumors (18\%). ${ }^{16,17}$ Embryonal carcinoma has also been reported. Walsh et al concluded that the chances of malignancy are six times higher in cryptorchidism where operation was delayed until after 10 years. ${ }^{17}$ After mobilization of cord the ectopic testis can be fixed in the ipsilateral hemiscrotum (orchiopexy) either extra-peritoneal or trans-septal. In cases where vas deference's are fused and it is difficult to perform extra-peritoneal ipsilateral orchiopexy ${ }^{13}$. Trans-septal orchiopexy can be considered.

\section{CONCLUSION}

TTE is a rare congenital anomaly. Exact pathogenesis is not clear. Fusion of Mullerian duct or descent along a rudimentary branch of gubernaculum are possible. Testis may be present in opposite hemi-scrotum, inguinal canal or at deep ring. Diagnosis should be suspected when a child presents with unilateral inguinal hernia and opposite testis is not palpable. However, diagnosis is usually made during surgery. Preoperative ultrasound and laparoscopy may help in diagnosis if suspected clinically. Extra-peritoneal ipsilateral orchiopexy is recommended when vas and its vessels can be mobilized easily. In difficult cases of vas fusion, trans-septal orchiopexy should be considered. Post-operative scan should be done for any rudimentary uterus (Mullerian duct syndrome), pseudo-hermaphroditism.

Copyright(C) 15 Apr, 2016.

\section{REFERENCES}

1. Acikalin MF, Pasaoglu O, Tokar B, Ilgici D, Ilhan H. Persistent Mullerian duct syndrome with transverse testicular ectopia: a case report with literature. Turk J 
Med Sci. 2004;34:333-6.

2. Berkmen F. Persistent Müllerian duct syndrome with or without transverse testicular ectopia and testis tumour. British J urol. 1997; 79 (1): 122-126.

3. Barrack S. Crossed testicular ectopia with fused bilateral duplication of the vasa deferential, an unusual finding in cryptorchidism. East African Medical Journal. 1994; 71 (6):398-400.

4. Campbell, M.F. Principles of Urology. Philadelphia, WB Sanders and Co, 1957, p.1999.

5. Chacko JK, Furness PD, Mingin GC. Presentation of fused vas deferens. Urology 2006 May; 67 (5): 1085. e17-18.

6. Dajani, A. M. Transverse ectopia of the testis. Br. J. Urol., 1969;4:80-82.

7. Feizzadeh KB, Mohamadzadeh RM. Crossed testicular ectopia: a case report. Urol J.2005;2(4):222-223.

8. Gornall PG, Pender DJ. Crossed testicular ectopia detected by laparoscopy. $\mathrm{Br} \mathrm{J}$ Urol. 1987;59(3).

9. Gupta RL, Das P. Ectopia testis transversa. J Indian Med Assoc. 1960;16:35:547-549.

10. Kimura T. Transverse ectopy of the testis with masculine uterus. Ann Surg. 1918;68(4):420-425.

11. McAninch JW: Disorders of the Testis, Scrotum, and Spermatic Cord. In: Tanagho EA. McAninch JW, (eds.), Smith's General Urology. USA: Prentice Hall International Inc., pp. 685-690, 1995.

12. Nam YS, Baik HK, Kim SJ, Lee HK, Park HK. Transverse testicular ectopia found by preoperative ultrasonography. J Korean Med Sci. 1998; 13(3):328330.

13. Rajfer, J. Technique oforchiopexy. Urol Clin North Am. 1982; 9 (3):422.

14. Rajfer: J. Congenital anomalies of the testes. In (ads) Patrick CW et al: Campbell's Urology 6th ed., Vol 2, Philadelphia, WB Sanders and Co., 1992, P. 1548.

15. Vaos G, Zavras N. Irreducible inguinal hernia due to crossed testicular ectopia in an infant. Hernia.2004;8(4):397-398.

16. Walsh TJ, Dall'Era MA, Croughan MS, Carroll PR, Turek PJ. Prepubertal orchiopexy for cryptorchidism may be associated with lower risk of testicular cancer. J Urol. 2007;178(4 Pt 1):1440-1446.

17. Wood HM, Elder JS. Cryptorchidism and testicular cancer: separating fact from fiction. J Urol.2009;181(2):452-461.

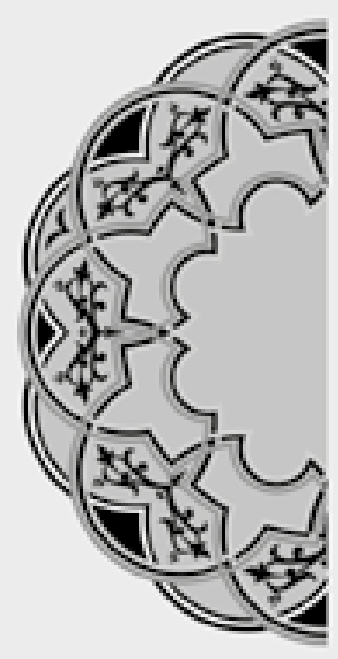

\section{"The wind cannot defeat a tree with strong roots."}

The Revenant Movie 2015

AUTHORSHIP AND CONTRIBUTION DECLARATION

\begin{tabular}{c|l|l|l|} 
Sr. \# & \multicolumn{1}{|c|}{ Author-s Full Name } & \multicolumn{1}{|c|}{ Contribution to the paper } & Author=s Signature \\
1 & Dr. Fayyaz Ahmad Orfi & $\begin{array}{l}\text { Concept, Operating } \\
\text { Surgeon } \\
\text { Research, References }\end{array}$ \\
2 & Dr. Saira Shakeel & Editing and Proof reading & \\
3 & Dr. Farrukh Shahzad &
\end{tabular}

